\title{
Urinary Retention
}

National Cancer Institute

\section{Source}

National Cancer Institute. Urinary Retention. NCI Thesaurus. Code C50790.

Accumulation of urine within the bladder because of the inability to urinate. 